\title{
COPD affects worker productivity and health care costs
}

This article was published in the following Dove Press journal:

International Journal of COPD

\author{
Jeetvan G Patel' \\ Anna D Coutinho² \\ Orsolya E Lunacsek ${ }^{2}$ \\ Anand A Dalal ${ }^{3}$ \\ 'Global Health Economics, \\ Amgen, Thousand Oaks, CA, USA; \\ ${ }^{2}$ AmerisourceBergen, Xcenda, \\ Palm Harbor, FL, USA; ${ }^{3}$ US Health \\ Economics and Outcomes Research, \\ Novartis Pharmaceuticals, \\ East Hanover, NJ, USA
}

Purpose: This study aimed to measure the true burden of COPD by calculating incremental direct and indirect costs. Direct medical resource use, productivity metrics, and COPD-specific resource use and costs were also evaluated.

Patients and methods: This was a retrospective, observational, matched cohort study using administrative claims data from the Truven Health MarketScan ${ }^{\circledR}$ Commercial Claims and Encounters and the Health and Productivity Management databases (2007-2010). Working-age (18-65 years) patients with COPD were identified as having at least one hospitalization or one emergency department visit or two outpatient visits. Patients in the non-COPD cohort did not have a diagnosis of COPD during the study period. Outcomes were evaluated in the first full calendar year after the year of identification (index).

Results: Of the 5,701 patients with COPD identified, 3.6\% patients were frequent exacerbators $(\geq 2), 10.4 \%$ patients were infrequent exacerbators (1), and $86 \%$ patients were non-exacerbators (0). When compared with the 17,103 patients without COPD, the incremental direct cost of COPD was estimated at \$6,246/patient/year (95\% confidence interval: $\$ 4,620, \$ 8,623$; $P<0.001)$. Loss in productivity was significantly greater in patients with COPD, with an average of 5 more days/year of absence from work and incremental indirect costs from short-term disability of $\$ 641(P<0.001)$. Direct costs for frequent exacerbators $(\$ 17,651 /$ year $)$ and infrequent exacerbators $(\$ 14,501 /$ year) were significantly higher than those for non-exacerbators $(\$ 11,395, P<0.001)$.

Conclusion: Working-age patients with COPD incur statistically significantly higher direct and indirect costs and use more resources compared with those who do not have COPD.

Keywords: COPD, productivity, cost, employer, exacerbation, resource

\section{Plain language summary}

Working-age patients with COPD are costly to employers and incur approximately twice as high costs as those without COPD. Productivity claims associated with COPD were responsible for $10 \%$ of the overall cost burden. This retrospective, observational, matched cohort study aimed to measure the true burden of COPD in insured, working individuals by calculating incremental direct and indirect costs. Direct costs for patients with frequent exacerbations were $22 \%$ higher than for patients with infrequent exacerbations and $55 \%$ higher than for those classified as non-exacerbators. This study reveals a number of statistically significant predictors of high incremental costs associated with COPD, for example, the frequency of exacerbations.

Correspondence: Orsolya E Lunacsek AmerisourceBergen, Xcenda, 4II4 Woodlands Parkway, Suite 500,

Palm Harbor, FL 34685, USA

$\mathrm{Tel}+1727$ 77I 4100

Email orsolya.lunacsek@xcenda.com

\section{Introduction}

COPD is a preventable and treatable disease. Common risk factors for COPD include exposure to tobacco smoke and smoke from biomass fuels. ${ }^{1}$ COPD is predicted to be 
the third leading cause of death by $2020 .{ }^{1,2}$ Direct health care expenditures for this chronic disease account for more than half ( $\$ 30$ billion) of the national projected economic cost for COPD (\$49.9 billion; 2010 estimate). ${ }^{3}$ Indirect morbidity costs, primarily associated with lost productivity, are responsible for $\$ 8$ billion of the projected total cost, and indirect mortality costs account for $\$ 14.8$ billion. ${ }^{4}$ A direct link between COPD severity and cost of care has been noted. ${ }^{1,5}$ Patients with very severe disease per Global Initiative for Chronic Obstructive Lung Disease 2010 criteria incurred up to six times the cost of a non-COPD control group. ${ }^{5}$ Similar trends have been reported elsewhere. ${ }^{3,6}$

Reduced lung function associated with COPD also has a negative impact on productivity, reducing a patient's ability to perform activities of daily living. ${ }^{7-9}$ COPD has been associated with 19.4 more days away from work (vacation, sick time, and disability) and 27.5 more days of lost productivity due to impaired performance at work compared with other chronic conditions. ${ }^{9}$ This is an important consideration since half of patients with COPD are in their productive, working years. ${ }^{10}$ Thus, COPD is a costly disease for an employer. ${ }^{11,12}$

While several studies have estimated the direct cost of COPD, a few have estimated both the direct and indirect costs, as a measure of the true burden of COPD. ${ }^{13,14}$ Furthermore, although a number of studies have assessed the impact of exacerbation frequency on direct costs, ${ }^{15-18}$ there is limited information on the impact of frequency of exacerbations on both direct and indirect costs in patients with COPD. Exacerbations in COPD are the dominant cause of COPD morbidity and mortality, ${ }^{19}$ estimated to account for $50 \%-75 \%$ of the direct health care costs for COPD. ${ }^{20}$ Therefore, it is important to highlight the incremental impact of these exacerbations on indirect costs. The current study seeks to provide incremental estimates of the direct and indirect burden of COPD using data from a nationally representative setting of working-age patients with COPD with employer-sponsored insurance. Furthermore, the impact of frequency of exacerbations on both direct and indirect costs was explored, and the predictors of high-cost patients with COPD were evaluated.

\section{Patients and methods Study design and sample selection}

This was a retrospective, observational, matched cohort study that used administrative claims data from the Truven Health MarketScan ${ }^{\circledR}$ Commercial Claims and Encounters (Commercial) and Health and Productivity Management (HPM) databases between January 1, 2007, and December 31, 2010.
The Commercial database, which represents the medical experience for $>50$ million insured employees and their dependants, was used to identify patient characteristics and calculate direct costs. The HPM database, which contains productivity metrics for almost 3 million employees, was used to estimate indirect costs. The MarketScan ${ }^{\circledR}$ databases fully comply with the Health Insurance Portability and Accountability Act of 1996 (HIPAA) and meet the requirements for fully de-identified datasets; therefore, ethical approval was not required for this study.

Working-age (18-65 years) patients in the COPD cohort were identified as having had at least one hospitalization or one emergency department (ED) visit or two outpatient visits with a diagnosis code for COPD (International Classification of Diseases, Ninth Revision, Clinical Modification codes: 491.xx, 492.xx, 496.xx) in any field during the identification period (2007-2009). Patients in the nonCOPD cohort were required to have at least one medical or prescription claim for any cause except COPD during the identification period and did not have a diagnosis of COPD during the study period. The earliest possible year during the identification period was chosen as the index year (12-month period) for each patient with COPD. Whichever year was used, the same year was used for the matched patient without COPD as the final index year. Patients with COPD were matched to patients in the non-COPD cohort in a 1:3 ratio using key baseline variables (age, gender, geographic region, health plan type, industry employment category, index year, and eligibility for absence or shortterm disability in the index and outcome years). After initial identification, patients aged $\geq 40$ years in the index year with eligibility for medical as well as absenteeism and/or short-term disability benefits in both the index and outcome years were included in the final sample eligible for matching. Patients were excluded from this final sample for missing or unknown values for any matching variable, evidence of pregnancy in the index or outcome year, or diagnosis of a condition associated with reduced lung function during the index or outcome year (list of conditions available upon request). Within the COPD cohort, patients were classified by the frequency of exacerbations: frequent $(\geq 2)$, infrequent (1), and non-exacerbator (0). A COPDrelated exacerbation was defined as a hospitalization or ED visit with a primary discharge diagnosis of a COPD event or a COPD-related physician visit with a primary diagnosis of a COPD event. In addition, patients had to have received an oral corticosteroid (OCS) or antibiotic prescription within 5 days of the physician visit. ${ }^{21}$ 


\section{Study outcomes}

For all patients, outcomes were evaluated in the calendar year (12-month period) after the index year. Incremental costs, defined as the difference in all-cause direct and indirect costs between patients with and without COPD in the outcome year (ie, 2008-2010), were used to estimate the costs incurred by COPD. Direct cost estimates were computed using paid amounts on all medical and pharmacy claims regardless of diagnosis. Indirect costs were estimated from the costs paid for short-term disability claims. All costs were adjusted to 2010 United States (US) dollar (USD) using the medical component of the Consumer Price Index.

Other end points evaluated included direct medical resource use (hospitalizations, ED visits, physician visits, outpatient visits, and other medical visits), productivity metrics (short-term disability, absenteeism for any reason, and sickness-related absenteeism), and COPD-specific resource use and costs.

\section{Statistical analyses}

A random-effects model was used to test the assumption that the within-clusters residual variance was similar across the matched cohorts. If the variance was low across the clusters $(<0.3)$, the within-clusters residual variance was assumed to be the same across all clusters and analyzed using a standard generalized estimating equation (GEE) model with a log-link using the appropriate distribution (usually gamma) without incorporating random effects. When variance was high $(>0.3)$, categorical outcomes, such as proportion of patients using different medical resources, were analyzed using a multivariable conditional logistic regression model. Continuous outcomes, such as productivity metrics, were evaluated using GEE models with an identity link and a normal distribution. Comorbidities that were not usually theorized to be associated with COPD were adjusted for in all multivariate models to eliminate excess costs due to unrelated conditions. All multivariate models were also adjusted for comorbidities with diagnosis codes that comprised the Charlson Comorbidity Index (CCI), including cardiovascular disease (CVD) and respiratory conditions that have been shown to be associated with COPD and related outcomes. All statistical analyses were conducted using $\mathrm{SAS}^{\circledR}$ version 9.2 (SAS Institute Inc., Cary, NC, USA) with an a priori significance level of 0.05 .

\section{Results}

A total of 6,113 patients with COPD and 128,935 patients without COPD met all study criteria and were available for matching. The final matched sample included 22,804 patients $(5,701$ patients with COPD and 17,103 patients without COPD). Within the COPD cohort, $3.6 \%$ of patients were classified as frequent exacerbators, $10.4 \%$ as infrequent exacerbators, and $86 \%$ as non-exacerbators.

The average age of this working-age COPD cohort was 53 years, with the majority being males $(65.7 \%$; Table 1$)$. The majority of the patients ( $81 \%)$ were eligible for shortterm disability benefits but not absenteeism, $3 \%$ were eligible for absenteeism but not short-term disability, and 16\% were eligible to incur both. The COPD cohort had higher overall disease burden versus the non-COPD cohort, based on the higher CCI score of 0.88 versus 0.36 . The proportion of patients with COPD-related comorbidities (ie, asthma, upper respiratory tract infection [URTI], lower respiratory tract infection, depression, and CVD) and comorbidities included in the CCI was also higher for the COPD cohort.

\section{Direct costs and resource utilization}

Patients with COPD incurred costs that were almost twice as high as costs for patients without COPD, after adjusting for comorbidities ( $\$ 11,984$ vs $\$ 5,738$; Figure 1). Thus, the incremental per-patient direct cost of COPD was estimated at $\$ 6,246 /$ year $(95 \%$ confidence interval [CI]: $\$ 4,620$, $\$ 8,623 ; P<0.001)$. Both medical and pharmacy costs were significantly higher for patients with COPD compared with patients without COPD. The difference in medical costs averaged $\$ 4,653$. Patients with COPD also had a significantly higher resource use for all medical visits in all sites of care (Table 2) relative to patients in the non-COPD cohort. Patients with COPD had significantly more than twice the odds of having a hospitalization or ED visit compared with patients in the non-COPD cohort. Furthermore, they had three more physician visits/year compared with patients without COPD $(P<0.001)$.

When assessing costs by exacerbator status, as expected, direct costs increased with the frequency of exacerbations. Frequent exacerbators averaged $\$ 17,651$ year and infrequent exacerbators \$14,501/year. Both groups had significantly higher costs than non-exacerbators $(\$ 11,395, P<0.001$, compared with both groups). When evaluating COPD-specific costs (ie, cost for medical claims with a primary COPD diagnosis and pharmacy claims for COPD-related drugs), a similar pattern was observed. The predicted COPD-specific costs for both frequent exacerbators $(\$ 4,361)$ and infrequent exacerbators $(\$ 2,266)$ were statistically significantly higher than the cost for non-exacerbators $(\$ 644 ; P<0.001$, compared with both cohorts). All-cause resource utilization 
Table I Study sample description during index year after matching

\begin{tabular}{|c|c|c|}
\hline Characteristics & $\begin{array}{l}\text { COPD } \\
(n=5,701)\end{array}$ & $\begin{array}{l}\text { Matched control } \\
(n=17,103)\end{array}$ \\
\hline \multicolumn{3}{|l|}{ Variables used in match } \\
\hline Age (mean, SD) & $53(5.5)$ & $53(5.5)$ \\
\hline Male (n, \%) & $3,746(65.7)$ & II,238 (65.7) \\
\hline \multicolumn{3}{|l|}{ Region (n, \%) } \\
\hline Northeast & $988(17.3)$ & $2,964(17.3)$ \\
\hline North Central & $2,128(37.3)$ & $6,384(37.3)$ \\
\hline South & $\mathrm{I}, 894(33.2)$ & $5,682(33.2)$ \\
\hline West & $691(12.1)$ & $2,073(12.1)$ \\
\hline \multicolumn{3}{|l|}{ Plan type (n, \%) } \\
\hline Comprehensive & $321(5.6)$ & $963(5.6)$ \\
\hline $\mathrm{HMO}$ & $976(17.1)$ & $2,928(17.1)$ \\
\hline PPO & $3,913(68.6)$ & $11,739(68.6)$ \\
\hline Othera & $491(8.6)$ & $\mathrm{I}, 473(8.6)$ \\
\hline \multicolumn{3}{|l|}{ Index year (n, \%) } \\
\hline 2007 & $2,193(38.5)$ & $6,579(38.5)$ \\
\hline 2008 & $\mathrm{I}, 805(3 \mathrm{I} .7)$ & $5,415(31.7)$ \\
\hline 2009 & I,703 (29.9) & $5,109(29.9)$ \\
\hline \multicolumn{3}{|l|}{ Eligibility type (n, \%) } \\
\hline Absence+short-term disability & $897(15.7)$ & $2,691(15.7)$ \\
\hline Absence only & $187(3.3)$ & $56 \mid(3.3)$ \\
\hline Short-term disability only & $4,617(81.0)$ & $|3,85|(8 \mid .0)$ \\
\hline \multicolumn{3}{|l|}{ Industry $(\mathrm{n}, \%)$} \\
\hline Oil and gas extraction, mining & $104(1.8)$ & $312(1.8)$ \\
\hline Manufacturing, durable goods & $2,970(52.1)$ & $8,910(52.1)$ \\
\hline Manufacturing, non-durable goods & $989(17.3)$ & $2,967(17.3)$ \\
\hline Transportation, communications, utilities & $811(14.2)$ & $2,433(14.2)$ \\
\hline Retail trade & $28(0.5)$ & $84(0.5)$ \\
\hline Finance, insurance, real estate & $652(11.4)$ & $1,956(11.4)$ \\
\hline Services & $147(2.6)$ & $44 I(2.6)$ \\
\hline \multicolumn{3}{|l|}{ Variables not used in match } \\
\hline $\mathrm{CCl}$ (mean, SD) & $0.88(1.2)$ & $0.36(0.8)$ \\
\hline \multicolumn{3}{|l|}{ Individual $\mathrm{CCl}$ comorbidities (n, \%) } \\
\hline Myocardial infarction & $145(2.5)$ & $104(0.6)$ \\
\hline Congestive heart failure & $388(6.8)$ & $253(1.5)$ \\
\hline Peripheral vascular disease & $334(5.9)$ & $216(1.3)$ \\
\hline Dementia & $16(0.3)$ & $9(0.1)$ \\
\hline Respiratory diagnosis & $1,517(26.6)$ & $725(4.2)$ \\
\hline Connective tissue disease & $114(2.0)$ & $168(1.0)$ \\
\hline Peptic ulcer disease & $55(1.0)$ & $52(0.3)$ \\
\hline Mild liver disease & $102(1.8)$ & $1 \mathrm{II}(0.6)$ \\
\hline Diabetes & $878(15.4)$ & $1,975(11.5)$ \\
\hline Plegia & $9(0.2)$ & $15(0.1)$ \\
\hline Renal & $75(1.3)$ & $117(0.7)$ \\
\hline Diabetes complications & $157(2.8)$ & $295(1.7)$ \\
\hline Malignant cancer tumors & $258(4.5)$ & $640(3.7)$ \\
\hline Moderate/severe liver disease & $2(0.0)$ & $9(0.1)$ \\
\hline Metastatic tumors & $23(0.4)$ & $5 I(0.3)$ \\
\hline AIDS & $22(0.4)$ & $27(0.2)$ \\
\hline CVD & $348(6.1)$ & $307(1.8)$ \\
\hline Number of unique RXs (mean, SD) & $10.6(6.7)$ & $5.2(4.5)$ \\
\hline Number of unique DXs (mean, SD) & II.6 (7.0) & $6.5(5.1)$ \\
\hline \multicolumn{3}{|l|}{ Presence of specific comorbidities (n, \%) } \\
\hline Asthma & $\mathrm{I}, \mathrm{I} 60(20.3)$ & $495(2.9)$ \\
\hline URTI & $\mathrm{I}, 40 \mathrm{I}(24.6)$ & $2,832(16.6)$ \\
\hline LRTI & $1,619(28.4)$ & $1,112(6.5)$ \\
\hline $\mathrm{CVD}^{\mathrm{b}}$ & $2,916(51.1)$ & $6,156(36.0)$ \\
\hline Depression & $672(11.8)$ & $1,034(6.0)$ \\
\hline
\end{tabular}

Notes: ${ }^{\circ}$ Other health plans include capitated and non-capitated point of service, exclusive provider organizations, consumer-directed health plan, and high-deductible health plan. ${ }^{b}$ Several $\mathrm{CCl}$ cardiovascular categories.

Abbreviations: AIDS, acquired immunodeficiency syndrome; CCl, Charlson Comorbidity Index; CVD, cardiovascular disease; DX, diagnosis; HMO, health maintenance organization; LRTI, lower respiratory tract infection; PPO, preferred provider organization; RX, prescription; SD, standard deviation; URTI, upper respiratory tract infection. 


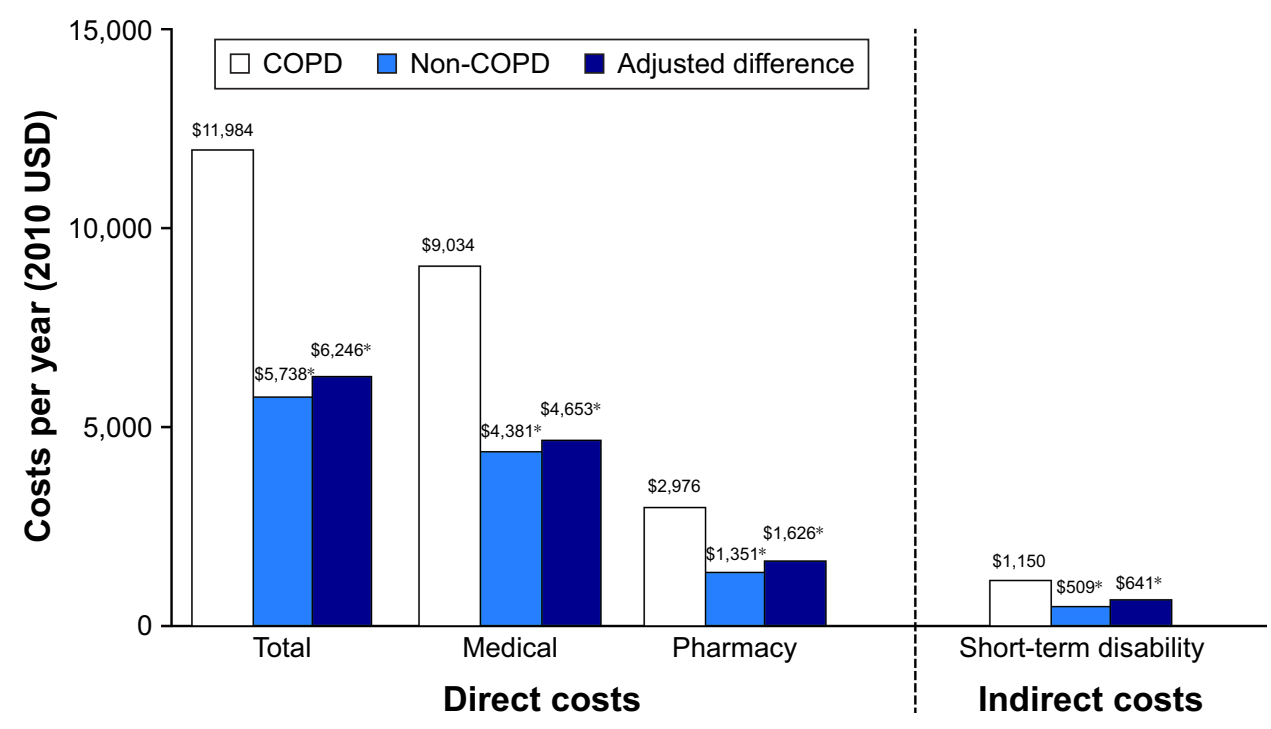

Figure I Annual adjusted direct and indirect costs between COPD and non-COPD cohorts.

Notes: Sample evaluated - direct costs: COPD ( $n=5,701)$ and non-COPD ( $n=17,103)$ and short-term disability: COPD ( $=5,5 \mid 4)$ and non-COPD ( $=16,542) .{ }^{a} A d j u s t e d$ for comorbidities included in the $\mathrm{CCl}$, including those associated with COPD. $* P<0.00 \mathrm{I}$.

Abbreviations: $\mathrm{CCl}$, Charlson Comorbidity Index; USD, US dollar.

of every visit type was highest for frequent exacerbators, followed by infrequent exacerbators and non-exacerbators, in terms of both the proportion of patients seeking care and the average number of visits/year (data not shown).

\section{Indirect costs and productivity}

Only those patients who were eligible for absenteeism and/or short-term disability benefits were included in the respective indirect cost and productivity analyses. Approximately $19 \%$ of the full study group was eligible for absenteeism benefits, and close to $97 \%$ was eligible for short-term disability. On average, patients with COPD incurred $\$ 641$ higher costs due to short-term disability compared with patients in the nonCOPD cohort (Figure 1). Thus, the incremental indirect and direct cost burden due to COPD averaged $\sim \$ 7,000 /$ year.

Although patients with COPD had a slightly higher likelihood of incurring absenteeism for any reason than patients without COPD, this difference was not significant (Table 2).

Table 2 Annual adjusted ${ }^{\text {a }}$ differences in health care resource use and productivity metrics

\begin{tabular}{|c|c|c|c|c|}
\hline $\begin{array}{l}\text { Health care resource usel } \\
\text { productivity metrics }\end{array}$ & COPD & Non-COPD & Adjusted difference & $\begin{array}{l}\text { Odds ratio }(95 \% \mathrm{Cl}) \text { for } \\
\text { incurring use or productivity } \\
\text { measure (ref: non-COPD) }\end{array}$ \\
\hline \multicolumn{5}{|l|}{ Medical resource use (no. of visits per year) } \\
\hline Sample evaluated ${ }^{b}$ & $n=5,70 I$ & $n=17,103$ & & \\
\hline Hospitalizations & 0.19 & 0.06 & $0.13^{*}(0.09,0.18)$ & $2.79 *(2.5 I, 3.1 I)$ \\
\hline ED visits & 0.41 & 0.18 & $0.23 *(0.18,0.29)$ & $2.14 *(1.98,2.31)$ \\
\hline Physician visits & 7.11 & 4.30 & $2.82 *(2.52,3.14)$ & $2.17 *(1.93,2.43)$ \\
\hline Outpatient visits & 7.28 & 5.39 & $1.89 *(1.47,2.38)$ & $1.25 *(1.15,1.36)$ \\
\hline Other visits & 1.43 & 0.31 & $1.12 *(0.73,1.91)$ & $2.87^{*}(2.62,3.15)$ \\
\hline \multicolumn{5}{|l|}{ Productivity metrics } \\
\hline \multicolumn{5}{|l|}{ Absenteeism } \\
\hline Sample evaluated ${ }^{\mathrm{b}}$ & $\mathrm{n}=\mathrm{I}, 084$ & $n=3,252$ & & \\
\hline Absence any reason (hours per year) & 320.7 & 276.8 & $43.9 *(30.5,57.3)$ & $1.21(0.88,1.66)$ \\
\hline Sickness-related absence (hours per year) & 56.3 & 41.8 & $14.4 *(8.9,19.9)$ & $1.59 *(1.34,1.90)$ \\
\hline \multicolumn{5}{|l|}{ Short-term disability } \\
\hline Sample evaluated & $n=5,5 I 4$ & $n=16,542$ & & \\
\hline Mean days per year & 12.6 & 5.0 & $7.6 *(6.7,8.4)$ & $2.58^{*}(2.37,2.8 I)$ \\
\hline
\end{tabular}

Notes: Values are predicted estimates $(95 \% \mathrm{Cl}$ shown for difference). $* \mathrm{P}<0.00 \mathrm{I}$. adjusted for comorbidities included in the $\mathrm{CCl}$, including those associated with $\mathrm{COPD}$ bIncludes those having eligibility for medical and pharmacy benefits (for direct costs), absenteeism benefits (for absenteeism), and short-term disability benefits (for shortterm disability).

Abbreviations: $\mathrm{Cl}$, confidence interval; $\mathrm{ED}$, emergency department. 


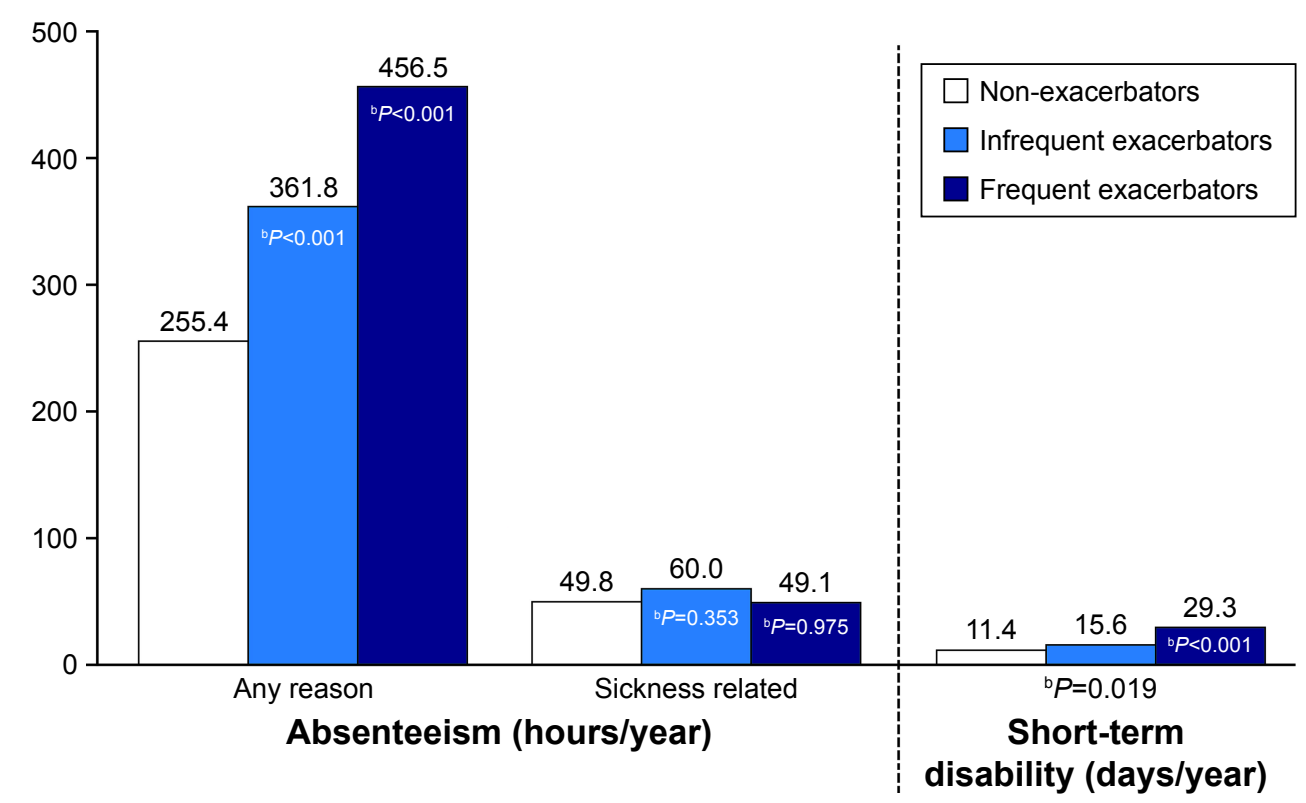

Figure 2 Annual adjusted ${ }^{\mathrm{a}}$ productivity metrics by exacerbator status.

Notes: ${ }^{a}$ Adjusted for comorbidities included in the $\mathrm{CCl}$, including those associated with COPD. ${ }^{b} \mathrm{P}$-value - compared with non-exacerbators.

Abbreviation: $\mathrm{CCl}$, Charlson Comorbidity Index.

However, patients with COPD did have significantly more absenteeism hours relative to patients without COPD with an average of 44 more hours missed/year, which represents a difference of $\sim 5$ days/year. When evaluating only sicknessrelated absence, patients with COPD had 60\% higher odds of taking a sick day compared with patients without COPD, with a significant difference of 14 hours or 1.5 days/year $(P<0.001)$. Patients with COPD had almost 2.6 times the odds of incurring short-term disability with an average of eight more disability days/year than patients without COPD (Table 2).

When assessing indirect costs and productivity metrics by exacerbator status, frequent and infrequent exacerbators had significantly higher absenteeism hours for any reason compared with non-exacerbators $(P<0.001$ for both groups vs non-exacerbators; Figure 2). Sickness-related absenteeism hours, while higher for these two subgroups, did not differ when compared with those of non-exacerbators (Figure 2).

The number of short-term disability days was significantly higher for both frequent and infrequent exacerbators; frequent exacerbators had more than two times the number of short-term disability days compared with non-exacerbators (29.3 vs 11.4, $P<0.001$; Figure 2). This translated into a significantly higher short-term disability cost difference of $\$ 2,857 /$ year for frequent exacerbators compared with nonexacerbators (Figure 3). Short-term disability costs for infrequent exacerbators, although higher, were not statistically significant compared with those for non-exacerbators.

\section{Predictors of high costs}

When defining patients whose overall cost was above the 90th percentile of the cost distribution $(\$ 33,408)$ as highcost patients, the multivariate analysis returned many statistically significant predictors of high cost (Figure S1): frequent exacerbator type, infrequent exacerbator type, CCI, depression, number of prescription fills for OCS, and total

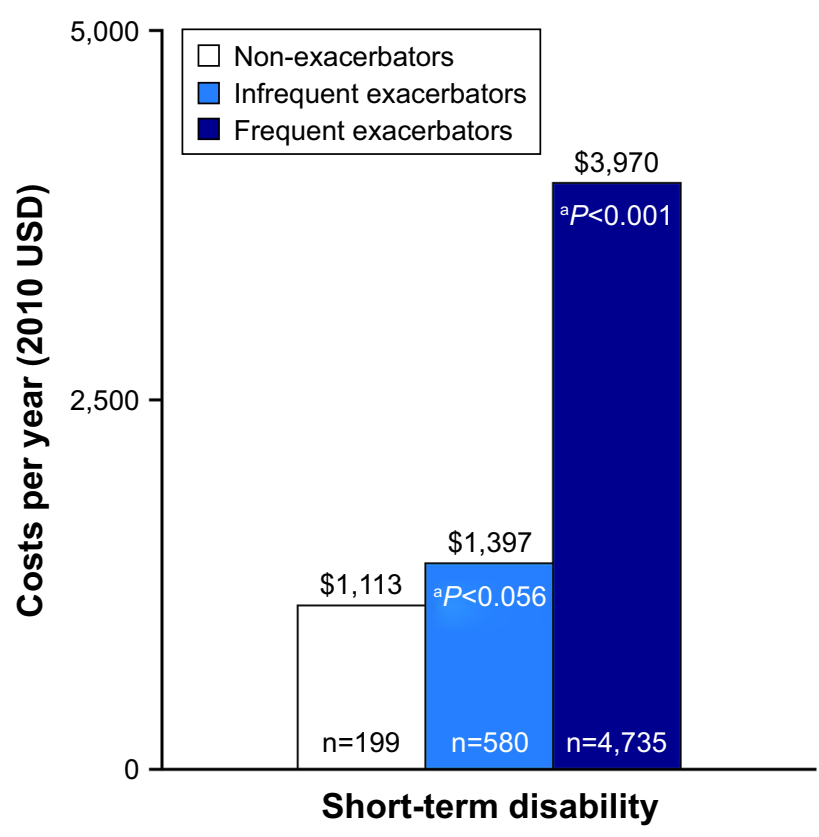

Figure 3 Adjusted indirect costs per year by exacerbator status. Note: ${ }^{a}$-value - compared with non-exacerbators. Abbreviation: USD, US dollar. 
direct all-cause cost in the index year. Sensitivity analysis defining patients whose overall cost was above the 85 th percentile of the cost distribution $(\$ 24,127)$ as high-cost patients revealed two additional covariates as statistically significant predictors: URTI (odds ratio: 1.3 ; 95\% CI: 1.04 , $1.5 ; P=0.015)$ and total indirect cost in the index year (odds ratio: $1.03 ; 95 \% \mathrm{CI}: 1.01,1.05 ; P=0.004)$.

\section{Discussion}

The aim of this study was to evaluate the incremental economic burden due to COPD, assessing both direct and indirect costs. Overall, the results suggest that insured, working-age patients with COPD incurred approximately twice the costs of patients without COPD, resulting in $\sim \$ 6,000 /$ year in incremental direct costs. In addition, patients with COPD incurred higher productivity losses due to their disease. This resulted in $\$ 641 /$ year in incremental costs due to short-term disability claims. Thus, the per-patient incremental burden due to COPD can be estimated to be $\$ 6,650 /$ year, of which $10 \%$ is due to productivity losses.

Our study findings were confirmed by a similar database study by Nair et $\mathrm{al}^{14}$ that used the same data source as our study, albeit using data until 2007 versus data after 2007 as in our study. The incremental direct cost due to COPD was found to be much higher in the current study compared with that in the study by Nair et $\mathrm{al}^{14}$ ( $\$ 6,000$ vs $\left.\$ 3,600\right)$; however, indirect costs were slightly lower in our study (\$641 vs \$909). Indirect costs accounted for $\sim 20 \%$ of the total costs in the study of Nair et al, which were higher than the $10 \%$ costs due to productivity losses in our study. Importantly, despite showing higher absenteeism in patients with COPD, we had insufficient data to allow inclusion of the associated costs; therefore, the indirect costs are likely to be underestimated. Other studies have reported productivity losses amounting to $37 \%-41 \%$ of the total costs of COPD. ${ }^{2,22}$ These studies also included morbidity or presenteeism data in computing indirect costs, which likely account for the higher percentage compared with our study.

Several studies of working-age patients with COPD in the US assessing productivity metrics but not costs have found these measures to be significantly higher in patients with COPD compared with those without COPD..$^{7,911,22,23}$ Of note, workers with COPD had the largest risk of being absent due to their condition compared with those with depression, anxiety, or emotional disorder and migraine/chronic headaches. ${ }^{11}$ On average, patients with COPD in our study had 56 hours/year of sicknessrelated absenteeism, similar to the value found in another study where patients with COPD reported 1.08 hours/week
(52 hours/year) lost due to absenteeism. ${ }^{23}$ In general, patients with COPD have 1.2-1.5 times the rate of absenteeism and short-term disability as patients without COPD, as seen in the current study and the study of Nair et al. ${ }^{14}$

Although there are limited data relating the frequency of exacerbations to indirect costs, data from the Confronting COPD survey in Europe have shown that indirect costs change with disease severity, increasing from 4 to 17 times from mild to severe disease. ${ }^{24,25}$ A study of working-age patients with COPD in the US found that more severe disease was associated with a greater reduction in workforce participation $(3.4 \%, 3.9 \%$, and $14.4 \%$ for mild, moderate, and severe COPD, respectively). ${ }^{26}$ In our study, all patients were in the workforce, but an incremental effect was observed with an increasing number of exacerbations with distinct differences noted between frequent exacerbators compared with infrequent and non-exacerbators in the number of short-term disability days. Unfortunately, the low sample size limits the interpretation of the impact of frequency of exacerbations on absenteeism in the current study. The recent work by the study authors has found frequent exacerbators to have almost two times higher COPD-related costs on a per-patient level compared with infrequent exacerbators ( $\$ 7,400$ vs $\$ 3,900)$, but on a population-level, infrequent exacerbators accounted for a higher proportion of patients with COPD and were similar if not more burdensome compared with frequent exacerbators in terms of their percentage share of the total COPD-related costs (23\% vs $18 \%){ }^{4}$

In this study, models were adjusted for comorbidities included in the CCI rather than a comprehensive list of possible comorbidities, meaning that some conditions may not have been accounted for. Furthermore, our estimate of indirect costs only accounts for short-term disability and not absenteeism, presenteeism, or long-term disability. This may underestimate costs for an employer. Moreover, short-term disability data were extracted from the MarketScan database, the reliability and consistency of which have not been confirmed. In addition, we evaluated the outcomes in the calendar year after the index year, regardless of when diagnosis was made. Should patients have been diagnosed in the beginning of the index year, thereby beginning outcomes recording a full year after diagnosis, costs may have been underestimated.

Another limitation of our analysis was the assessment of exacerbator status that used medical claims for defining exacerbator groups in the same period as outcomes; this potentially confounded the impact of exacerbations on direct costs. Unlike direct costs, the data for indirect costs were not confounded by exacerbator classification as no productivity 
metrics were used for exacerbator classification. However, larger samples are required to further corroborate the impact of exacerbator status on productivity metrics and participation in the workforce. As for other database studies, this analysis was limited by the data available within the database. Patients were all of working age, insured, and employed, potentially reducing the generalizability of the findings to the overall US population.

Notwithstanding the limitations, the study findings have highlighted the importance of assessing indirect costs and productivity outcomes in a COPD population and emphasized the need for future research to consider the impact of productivity and indirect cost outcomes in comparative effectiveness research evaluating various COPD treatment modalities.

\section{Conclusion}

Results of our database study demonstrate that working-age patients with COPD incur approximately twice the costs of patients without COPD and use more resources including hospitalizations and short-term disability days. While direct costs are substantial, indirect costs comprise at least $10 \%$ of the overall economic burden of COPD and emphasize the need for targeted disease management efforts to reduce the impact of the disease on worker productivity.

\section{Data sharing statement}

The dataset supporting the conclusions of this article is available from the authors upon reasonable request.

\section{Acknowledgments}

This study was funded by GSK (GSK study number HO-11736). Study conduct and data analysis were performed by Xcenda and funded by GSK. No funding was provided to the authors of Xcenda for manuscript development. The work presented here, including the conduct of the study, data analysis, and interpretation, was supported by GSK. Editorial assistance in the preparation of the manuscript (in the form of collating author comments, grammatical editing, and referencing) was provided by Joanne Ashworth and Elizabeth Jameson, PhD, of Fishawack Indicia Ltd, UK, and was funded by GSK.

\section{Author contributions}

All authors were involved in the conceptualization and design of the study, the acquisition of data, the data analysis and interpretation. All authors contributed to critically drafting and revising the paper, have provided final approval of the version to be published and agree to be accountable for all aspects of the work.

\section{Disclosure}

JGP and AAD were employees of GSK at the time of the study conduct. JGP is currently an employee of Amgen and owns stocks/shares. AAD is currently an employee of Novartis Pharmaceuticals and owns stocks/shares. ADC and OEL are employees of Xcenda, a health care consulting company contracted by GSK for the conduct of this study. The authors report no other conflicts of interest in this work.

\section{References}

1. Global Initiative for Chronic Obstructive Lung Disease. Global Strategy for the Diagnosis, Management and Prevention of Chronic Obstructive Pulmonary Disease. 2018. Available from: http://goldcopd.org/ wp-content/uploads/2017/11/GOLD-2018-v6.0-FINAL-revised-20Nov_WMS.pdf. Accessed April 27, 2018.

2. National Heart Lung and Blood Institute. Morbidity and Mortality: 2009 Chart Book on Cardiovascular, Lung and Blood Diseases. 2009. Available from: https://ecopmc.files.wordpress.com/2012/04/2009_chartbook.pdf. Accessed May 16, 2018.

3. Guarascio AJ, Ray SM, Finch CK, Self TH. The clinical and economic burden of chronic obstructive pulmonary disease in the USA. Clinicoecon Outcomes Res. 2013;5:235-245.

4. Patel JG, Nagar SP, Dalal AA. Indirect costs in chronic obstructive pulmonary disease: a review of the economic burden on employers and individuals in the United States. Int J Chron Obstruct Pulmon Dis. 2014;9:289-300.

5. Report MC. Chronic Obstructive Pulmonary Disease (COPD): An Actuarial Analysis of Drug Therapy Treatment Patterns for a Commercially Insured Population. 2011. Available from: http://www.milliman. com/uploadedFiles/insight/research/health-rr/chronic-obstructivepulmonary-disease.pdf. Accessed June 21, 2013.

6. Hilleman DE, Dewan N, Malesker M, Friedman M. Pharmacoeconomic evaluation of COPD. Chest. 2000;118(5):1278-1285.

7. Darkow T, Kadlubek PJ, Shah H, Phillips AL, Marton JP. A retrospective analysis of disability and its related costs among employees with chronic obstructive pulmonary disease. J Occup Environ Med. 2007; 49(1):22-30.

8. Mannino DM, Homa DM, Akinbami LJ, Ford ES, Redd SC. Chronic obstructive pulmonary disease surveillance-United States, 1971-2000. MMWR Surveill Summ. 2002;51(6):1-16.

9. Wang PS, Beck A, Berglund P, et al. Chronic medical conditions and work performance in the health and work performance questionnaire calibration surveys. J Occup Environ Med. 2003;45(12):1303-1311.

10. American Association for Respiratory Care [webpage on the Internet]. Confronting COPD in America: Executive Summary. 2011. Available from: https://c.aarc.org/resources/confronting_copd/exesum.pdf. Accessed May 16, 2018.

11. Collins JJ, Baase CM, Sharda CE, et al. The assessment of chronic health conditions on work performance, absence, and total economic impact for employers. J Occup Environ Med. 2005;47(6):547-557.

12. Goetzel RZ, Hawkins K, Ozminkowski RJ, Wang S. The health and productivity cost burden of the "top 10" physical and mental health conditions affecting six large U.S. employers in 1999. JOccup Environ Med. 2003;45(1):5-14.

13. Foster TS, Miller JD, Marton JP, Caloyeras JP, Russell MW, Menzin J. Assessment of the economic burden of COPD in the U.S.: a review and synthesis of the literature. COPD. 2006;3(4):211-218. 
14. Nair K, Ghushchyan V, Van Den Bos J, et al. Burden of illness for an employed population with chronic obstructive pulmonary disease. Popul Health Manag. 2012;15(5):267-275.

15. Dalal AA, Patel J, D'Souza A, Farrelly E, Nagar S, Shah M. Impact of COPD exacerbation frequency on costs for a managed care population. J Manag Care Spec Pharm. 2015;21(7):575-583.

16. Dhamane AD, Moretz C, Zhou Y, et al. COPD exacerbation frequency and its association with health care resource utilization and costs. Int J Chron Obstruct Pulmon Dis. 2015;10:2609-2618.

17. Punekar YS, Shukla A, Mullerova H. COPD management costs according to the frequency of COPD exacerbations in UK primary care. Int $J$ Chron Obstruct Pulmon Dis. 2014;9:65-73.

18. Pasquale MK, Sun SX, Song F, Hartnett HJ, Stemkowski SA. Impact of exacerbations on health care cost and resource utilization in chronic obstructive pulmonary disease patients with chronic bronchitis from a predominantly Medicare population. Int J Chron Obstruct Pulmon Dis. 2012;7:757-764.

19. Wedzicha JA, Donaldson GC. Exacerbations of chronic obstructive pulmonary disease. Respir Care. 2003;48(12):1204-1213.

20. Simoens S, Decramer M. Pharmacoeconomics of the management of acute exacerbations of chronic obstructive pulmonary disease. Expert Opin Pharmacother. 2007;8(5):633-648.
21. Lee TA, Wilke C, Joo M, et al. Outcomes associated with tiotropium use in chronic obstructive pulmonary disease patients. Eff Health Care Res Rep. Epub 2009.

22. Rennard S, Decramer M, Calverley PM, et al. Impact of COPD in North America and Europe in 2000: subjects' perspective of confronting COPD international survey. Eur Respir J. 2002;20(4):799-805.

23. DiBonaventura M, Paulose-Ram R, Su J, et al. The impact of COPD on quality of life, productivity loss, and resource use among the elderly United States workforce. COPD. 2012;9(1):46-57.

24. Piperno D, Huchon G, Pribil C, Boucot I, Similowski T. The burden of COPD in France: results from the Confronting COPD survey. Respir Med. 2003;97(Suppl C):S33-S42.

25. Wouters EF. Economic analysis of the confronting COPD survey: an overview of results. Respir Med. 2003;97(Suppl C):S3-S14.

26. Sin D, Stafinski T, Ng Y, Bell N, Jacobs P. The impact of chronic obstructive pulmonary disease on work loss in the United States. Am J Respir Crit Care Med. 2002;165(5):704-707. 


\section{Supplementary material}

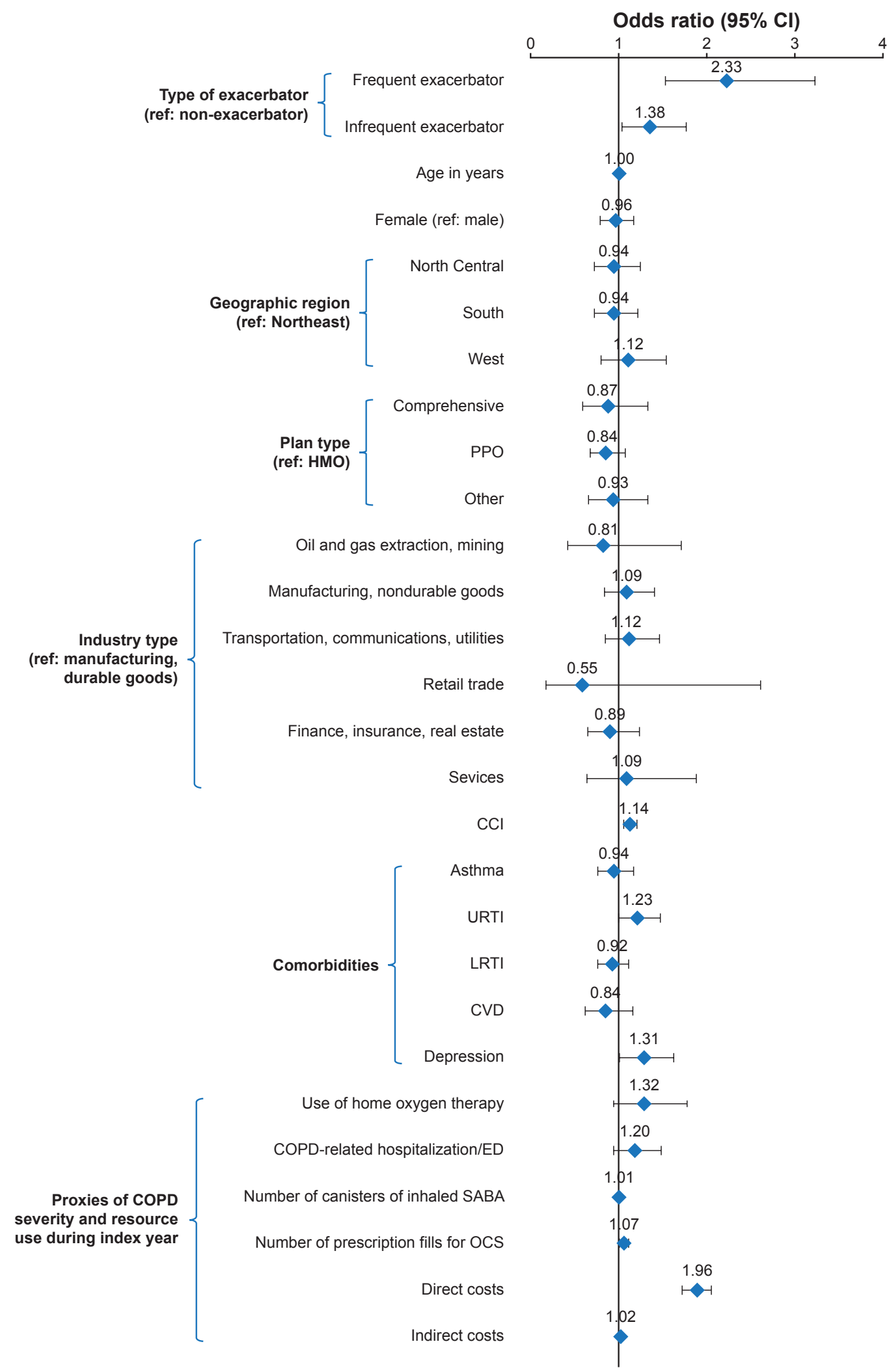

Figure SI Predictors of high cost: top 10 percentile of costs.

Abbreviations: CCI, Charlson Comorbidity Index; CVD, cardiovascular disease; ED, emergency department; HMO, health maintenance organization; LRTI, lower respiratory tract infection; OCS, oral corticosteroid; PPO, preferred provider organization; SABA, short-acting $\beta$-agonist; URTI, upper respiratory tract infection. 
International Journal of COPD

\section{Publish your work in this journal}

The International Journal of COPD is an international, peer-reviewed journal of therapeutics and pharmacology focusing on concise rapid reporting of clinical studies and reviews in COPD. Special focus is given to the pathophysiological processes underlying the disease, intervention programs, patient focused education, and self management protocols

\section{Dovepress}

This journal is indexed on PubMed Central, MedLine and CAS. The manuscript management system is completely online and includes a very quick and fair peer-review system, which is all easy to use. Visit $\mathrm{http}: / / \mathrm{www}$.dovepress.com/testimonials.php to read real quotes from published authors.

Submit your manuscript here: http://www.dovepress.com/international-journal-of-chronic-obstructive-pulmonary-disease-journal 